\title{
Methods Research to Calculate Equivalent of Environmental Cost in Power Industry
}

\author{
Wenchang Han1, Dunnan Liu², Yuhong Fan1, Yu Hu², Yujie Xu², Xinming Liu² \\ ${ }^{1}$ Electric Power Research Institute of Economics and Technology, Hubei Electric Power Company, Wuhan, China \\ ${ }^{2}$ School of Economics and Management, North China Electric Power University, Beijing, China \\ Email: hwccyxp@sina.com.cn, liudunnan@163.com, hhppyue@163.com, huyu0728@qq.com, \\ xuyujie0802@163.com
}

Received December 2013

\begin{abstract}
Power industry as an important means of primary energy consumption, occupies an important position in coal consumption and pollutant emissions, and causes a great impact on the environment. It is particularly important to define environmental costs while Environmental costs account for a heavy weight in the total cost of generating after the introduction of the Clean Development Mechanism (CDM) This paper analyzes the composition of environmental cost and its calculation methods, three cost equivalent pricing methods and its scope in environmental costs were proposed, there are Government pricing, market pricing and cost accounting, then analyses the cost of equivalent effect on electricity trade.
\end{abstract}

\section{Keywords}

Environmental Costs; Cost Equivalent; Pricing

\section{Introduction}

During the 11th Five-Year Plan to the 12th Five-Year plan, industrial energy conservation as a top priority, the power industry has a high standard of energy-saving emission reduction targets. Power generation plants will be limited under the constraints of energy-saving emission reduction [1]. In order to make coordination between emission reduction and power efficiency, the emission intensity of power generation companies should be restricted based on the CDM that the larger yield, the more emissions requirements. On the other hand, limits emissions of power plants have affected production decisions, or if mitigation measures are not taken to reduce production, it would spent more abatement costs. Therefore, before the power companies make a maximized benefit decisions. The pollutants emissions trading price and abatement costs need to be taken into account. This part of the costs not only provides reference for the cost of electricity in the power generation sector, but also has a significant impact on electricity trading.

Some calculation methods on abatement cost of emissions currently exist. Usually using the control costs divided emissions [2], but the mixing of pollutants will lead to an excessively high calculation results. Currently the "Kyoto Protocol" provides six kinds of anthropogenic greenhouse gases. In calculating the cost of these six gas, put them converted into $\mathrm{CO}_{2}$ according to a certain proportion [3]. But there is no specific calculation me- 
thod for $\mathrm{CO}_{2}$ abatement cost.

In summary, there are no relevant studies on the cost for each pollutant equivalent calculation methods. This article based on electricity trading background, classifies the pollutants according to the characteristics of the major environmental pollutants, and then proposes different solutions for each equivalent of pollutant cost.

\section{Cost Equivalent Description}

\subsection{The Origin of the Cost Equivalent}

In the electricity trading process, the transaction price is mainly derived from the total cost of electricity production. After the introduction of CDM, the total cost of power production includes production costs and environmental costs, as shown in Figure 1.

Environment abatement cost reflected with the passage of time. It will take some time that will affect trading decisions of the purchase and sale of electricity. Therefore, it's necessary to establish standards for the determination of environmental costs. In the power generation process, due to the differences between units, there will be a variety of different pollutants emissions. However, emissions of pollutants can be monitored in real time, so long as we know the cost of each pollutant equivalent, will be able to come to the environmental cost of the unit. This paper will define cost equivalent as the compensation paid which emission per unit to deal with environmental pollution.

\subsection{Environmental Cost Classification}

In this paper, environmental costs would be divided into resource consumption costs and the cost of pollution control, shown in Figure 2.

In this paper, resource consumption is mainly coal consumption. Coal consumption and water consumption costs are included in the cost of production, and therefore do not consider as constitute of environmental costs. Environmental costs mentioned in this article refer to the outside of this part of the production costs. In the environment of scarce resources, resource consumption will reduce part of the part, other companies are not able to use the resources while plants are using, so such plants need to pay an additional fee for the resources as opportunity cost.

Pollution category refers to affect the environment, including $\mathrm{CO}_{2}, \mathrm{SO}_{2}, \mathrm{NO}_{\mathrm{x}}$, solid particles and sewage. According to the scope of influence, the pollutions can be divided into three categories, namely global control, regional control and local control, shown in Figure 3.

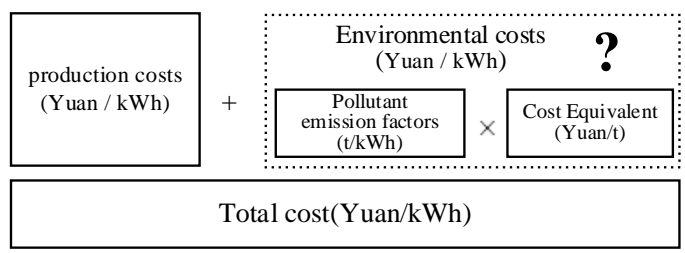

Figure 1. Composition of total costs.

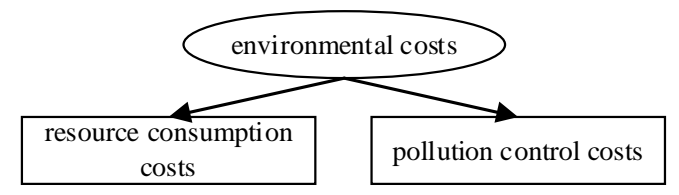

Figure 2. Composition of environmental costs.

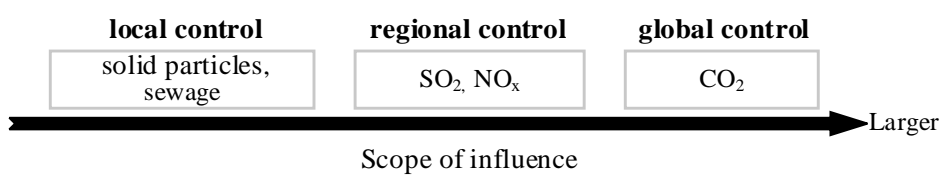

Figure 3. Composition of pollutant control. 
Where sewage and solid particles precipitated in the communication process, resulting in a small scope; $\mathrm{SO}_{2}$ and $\mathrm{NO}_{\mathrm{x}}$ emissions are gases, spread range farther; while $\mathrm{CO}_{2}$ emissions is huge, is the main greenhouse gases, have the largest of scope. According to the policy in different countries for the emission of pollutants will have certain restrictions and punishment. In order to limit emissions, it is necessary to take a series of measures, which spend a certain costs, and the costs constitute cost equivalent of pollutant control.

\section{Cost Equivalent Pricing Method}

According to the classification characteristics of the environmental costs, the paper proposes three pricing methods, and discusses the applicability analysis of the three pricing methods.

\subsection{Government Pricing}

Herein government pricing method can also be called analogy estimation method, principle of analogy estimation method is based on the resource tax, carbon taxes and emissions trading schemes that have been implemented at home and abroad, consider China's economic development, determined the emissions cost equivalent of resource tax and variety of pollutants by analogy estimation.

China only have resource tax levied, carbon tax policy has been not implemented. Then the carbon tax should be compared to determine, $\mathrm{CO}_{2}$ costs equivalent fluctuate around the carbon tax, and other pollutants estimate in accordance with the standard management for collecting the fee of discarded sewage.

1) Estimates of resource consumption cost equivalent

China has a corresponding resource tax regulations, the coal resource tax is between 0.3 and 5 Yuan/t, mainly based on the specific degree of contamination of the environment.

The degree of pollution is calculated in the region API (Air pollution Index) as follows:

$$
\operatorname{Tax}_{i}=\operatorname{Tax}_{\min }+\frac{A P I_{i}-A P I_{\min }}{A P I_{\max }-A P I_{\min }} \times\left(\operatorname{Tax}_{\max }-\operatorname{Tax}_{\min }\right)
$$

In Equation (1), $A P I_{\max }$ is the maximum $A P I$ value of nearly a year, $A P I_{\min }$ is the minimum $A P I$ value of nearly a year, $\left[\operatorname{Tax}_{\min }, \operatorname{Tax}_{\max }\right]$ is corresponding floating range of resource tax, $A P I_{i}$ is the API value for the calculation period.

2) Estimates of $\mathrm{CO}_{2}$ cost equivalent

Because $\mathrm{CO}_{2}$ is the most important factor of global warming, carbon cost equivalent can be considered as a global pollutant, the cost can be equivalent to a carbon tax as the standard of other countries, he U.S. carbon tax fee is 50 - 80 Yuan/t, Japanese carbon tax charges of 150 - 250 Yuan/t, the European Union is 200 - 300 Yuan/t [4], the standard of cost equivalent need to be based on the specific circumstances. In this paper, take GDP as an analog standard, combined with China's national conditions, the carbon tax fee is 50 Yuan/t.

3) Estimates of other pollutants cost equivalent

For $\mathrm{SO}_{2}$ and $\mathrm{NO}_{\mathrm{x}}$, according to The Regulation of Effluent Fees Collection, Usage and Management to calculate [5], $\mathrm{SO}_{2}$ and $\mathrm{NO}_{\mathrm{x}}$ pollution equivalent is 0.6 Yuan each. Calculation of pollution equivalent number is as follows:

$$
N_{i}=\frac{Q_{i}}{E_{i}}
$$

In Equation (2), $N_{i}$ is the equivalent number of corresponding pollutants, $Q_{i}$ is emissions of pollutants, $E_{i}$ is the pollution equivalents.

Because water and the solid particulate material comprise a contaminant, sewage and solid particles need to determine which according to the type and quantity of pollutants. Specifically, there is no policy to estimate cost equivalent, calculated as follows:

$$
C_{\text {sewage }}=0.7 \times \sum_{i=1}^{3} E_{i}
$$

In Equation (3), $\sum_{i=1}^{3} E_{i}$ represent the equivalents of top three pollutants. Calculation results are shown in Ta-

ble 1. 


\subsection{Market Pricing}

In the context of emissions trading, there is a certain total emissions limit each region, the total amount of emission rights directly affects the power generation, thus affecting their economic interests. The using of new energy, will not produce pollutants, so there will be no emission constraints, but due to higher new energy grid tariff, under the constraints of market trading mechanisms, the use of new energy sources to replace coal-fired power, need to meet the following constraints as follows:

$$
P_{\text {new }} \leq P_{\text {coal }}+C_{\text {environment }}
$$

The meaning of Equation (4) is that, the new energy grid tariff should be lessen or equal to sum of coal power grid tariff and environmental costs. $P_{\text {new }}$ is calculated by the following formula:

$$
P_{\text {new }}=P_{1} \cdot R_{1}+P_{2} \cdot R_{2}+\cdots+P_{n} \cdot R_{n}
$$

In Equation (5), $n$ represent for the new types of energy generation, $R_{n}$ represent for the proportion of the corresponding new energy, $P_{n}$ represent for corresponding benchmark price, the Table 2 shows the benchmark price of each new energy.

Above all, the results of environmental costs of 0.18 Yuan $/ \mathrm{kWh}$, based on AHP, come in the environmental cost factor's weighting coefficients in Table 3.

By pushing emission factors inversely, the results of the each cost equivalent as shown in Table 4.

\subsection{Cost Accounting}

During generation scheduling, power generation needs to be allocated according to the amount of power plant emissions, and whether the increasing benefits are greater than the additional cost of purchasing emission rights is the key to power business decisions. By calculating the discounted value of the difference in the initial investment and operating costs to install environmental equipment. Calculate the corresponding equivalent pollutants cost is calculated as described below.

1) The cash flows difference operations is calculated based on input and output values in the environmental protection installed around.

2) Obtained emission reductions corresponding to different types of environmental pollutants by measurement.

Table 1. Cost equivalent results based on government pricing.

\begin{tabular}{cccccc}
\hline Tax & $\mathrm{CO}_{2}$ & $\mathrm{SO}_{2}$ & $\mathrm{NO}_{\mathrm{x}}$ & $\mathrm{PM}$ & Sewage \\
\hline 3 & 50 & 631 & 631 & 1832.1 & 28 \\
\hline
\end{tabular}

Unit: Yuan/t.

Table 2. Benchmark price.

\begin{tabular}{ccccc}
\hline Thermal & Hydro & Wind & Solar & Nuclear \\
\hline 0.39 & 0.3 & 0.61 & 1.1 & 0.43 \\
\hline
\end{tabular}

Unit: Yuan/kWh.

Table 3. Weighting coefficients.

\begin{tabular}{cccccc}
\hline Tax & $\mathrm{CO}_{2}$ & $\mathrm{SO}_{2}$ & $\mathrm{NO}_{\mathrm{x}}$ & $\mathrm{PM}$ & Sewage \\
\hline 0.22 & 0.0003 & 0.2026 & 0.2046 & 0.37249 & 0.00001 \\
\hline
\end{tabular}

Table 4. Cost equivalent results based on market pricing.

\begin{tabular}{cccccc}
\hline Tax & $\mathrm{CO}_{2}$ & $\mathrm{SO}_{2}$ & $\mathrm{NO}_{x}$ & $\mathrm{PM}$ & Sewage \\
\hline 3.5 & 57 & 137 & 137 & 1023 & 3 \\
\hline
\end{tabular}


3) Different types of costs equivalent = cash flows difference/corresponding emission reductions.

\subsubsection{Benefit Analysis before Installation of Environmental Equipment}

Do not install the power plant environmental protection device (desulfurization, stock, dust, etc.), that is in the power generation process, the first emission of pollutants, the latter further treatment. In calculating the benefit, cash income is income from electricity sales; cash outflows include operating costs, and pollution control costs.

\subsubsection{Benefit Analysis after Installation of Environmental Equipment}

Power plants in the power generation process are in state of pollution control. After the installation of environmental equipment, cash inflows include sales income, national tariff compensation; cash outflows include fixed-asset investment, operating costs [6] during the period of initial operation, the supplies for environmental device desulfurization, denitrification. After desulfurization and denitrification, there are still emissions, so pollution control costs still exist, but reduce emissions.

\subsubsection{Comparative Analysis}

This section describes the NPV calculation among these two programs for one year, Table $\mathbf{5}$ is the basic data for calculation, use desulfurization unit as an example. The following calculation does not consider the generators fixed investment, investment lending rates.

The calculation period is 1 year, average total generation monthly, and the internal rate of return is $8 \%$. Therefore, the residual value of fixed assets a year later converted to a year ago counted as cash inflows. Using average depreciation as depreciation with 20 -year life. The depreciation equivalent to the first year of investment, as in.

$$
I_{\text {desulfurization }}=P V\left(8 \%, 12, E_{\text {residuals }}\right)
$$

In Equation (1), $E_{\text {residuals }}$ is the initial investment for the environmental unit minus the amount of depreciation for 12 months. Tables 6 and 7 respect for the statement of cash flows before and after installation of environmental equipment, because the average monthly generation, then the latter 11 months, have same cash flow.

The difference of NPV between the Tables $\mathbf{6}$ and $\mathbf{7}$ is the cumulative cost of sulfur equivalent. Cost equivalent for sulfur is 116.7 Yuan/t. According to the same method estimates, the cost of equivalent results obtained for each pollutant show in Table 8.

\section{Scope of Application}

The method described above has a different scope, shown in Figure 4.

1) Resource consumption. For the environmental costs of resource consumption costs equivalent class, because there is a clear national policy resource tax regulations, the coal consumption corresponding to the carbon tax by the government pricing, i.e. the carbon tax as a standard resource.

2) $\mathrm{CO}_{2}$ cost equivalent. Due to the large range impact of $\mathrm{CO}_{2}$, and in the European Union, the United States

Table 5. Basic data table.

\begin{tabular}{ccc}
\hline & before installation & installation \\
\hline Unit power (MW) & 300 & 300 \\
Generating hours (h) & 5000 & 5000 \\
Pool purchase price (Yuan/kWh) & 0.48 & 0.48 \\
Price subsidy (Yuan/kWh) & 0 & 0.015 \\
Invest (180 Yuan/kW) & 0 & $54,000,000$ \\
Operating costs (Yuan/kWh) & 0.089 & 0.095 \\
Running costs (Yuan/kWh) & 0 & 0.009 \\
Abatement costs (Yuan/kWh) & 0.087 & 0.025 \\
\hline
\end{tabular}


Table 6. Cash Flow before installation.

\begin{tabular}{ccc}
\hline & & $1-12$ \\
\hline Cash inflows & Generation(MWh) & $60,000,000$ \\
& 1. Electricity sales & 125,000 \\
& & $60,000,000$ \\
\hline Cash outflows & 2. Abatement costs & $22,000,000$ \\
& 3. Operating costs & $10,875,000$ \\
& & $11,125,000$ \\
\hline Net cash flow & $N P V$ & $38,000,000$ \\
\hline
\end{tabular}

Table 7. Cash Flow after installation.

\begin{tabular}{lccc}
\hline \multirow{2}{*}{ Cash inflows } & & 1 & $2-12$ \\
& & 82246935.82 & $61,875,000$ \\
& Generation(MWh) & 125,000 & 125,000 \\
& 1. Electricity sales & $60,000,000$ & $60,000,000$ \\
& 2. Price subsidy & $1,875,000$ & $1,875,000$ \\
& 3. Residuals & 20371935.82 & \\
\hline Cash outflows & & $70,125,000$ & $16,125,000$ \\
& 4. Unit Investment & $54,000,000$ & \\
& 5. Operating costs & $11,875,000$ & $11,875,000$ \\
& 6. Running costs & $1,125,000$ & $1,125,000$ \\
& 7. Abatement costs & $3,125,000$ & $3,125,000$ \\
\hline Net cash flow & & 12121935.82 & $45,750,000$ \\
\hline
\end{tabular}

Table 8. Cost equivalent results based on cost accounting.

\begin{tabular}{cccc}
\hline $\mathrm{SO}_{2}$ & $\mathrm{NO}_{x}$ & $\mathrm{PM}$ & sewage \\
\hline 116.7 & 272 & 915.7 & 1.8 \\
\hline
\end{tabular}

Unit: Yuan/t.

and other developed countries, the carbon tax system is more perfect, so pricing is determined by the government, also be based on China's national conditions through cost accounting method, market pricing can also be carried out in accordance with the carbon emissions trading market. In short, $\mathrm{CO}_{2}$ is one of the most common pollutants, and therefore the cost of equivalent can choose different pricing methods depending on the circumstances.

3) $\mathrm{SO}_{2}, \mathrm{NO}_{\mathrm{x}}$ cost equivalents. Because there are more comprehensive measures for $\mathrm{SO}_{2}, \mathrm{NO}_{\mathrm{x}}$ pollutants, so we can calculate the cost equivalent of using cost accounting method, but with the gradual improvement of emissions trading market, we can also determine the cost of equivalent through market pricing through competitive bidding.

4) Solid particles, sewage cost equivalents. Solid particles and sewage contains many contaminants, which are also different levels of pollutants, so only through cost accounting method, depending on the classification of generators to develop solid particles and sewage costs equivalent standards.

Table 9 shows the results of the three methods. 
Method (1) is related to macroeconomic policies, scope for all industries, the performance of a standard pollution control costs. Consider these three methods comprehensively, we can derive a pricing scope of cost equivalent for carbon tax and $\mathrm{CO}_{2}$, shows in Table 10.

But for the type of pollution control that have industry differences. It should be measures based on the method (2) and method (3) that approved for the power industry. The range of the results is shown in Table 11.

After obtaining cost equivalent by the above method, it is possible to calculate environmental costs, and then come to the total cost of generation. Usually in the purchase and sale decisions are costing method by calculating the cost of pollutants. In the part of purchase, we can subtract a series of cost because the purchase of electricity from other provinces and reduction in the amount of pollution generated locally; in the multilateral trading auction, the purchase price may declare this part of the cost equivalent to improve the successful rate. While

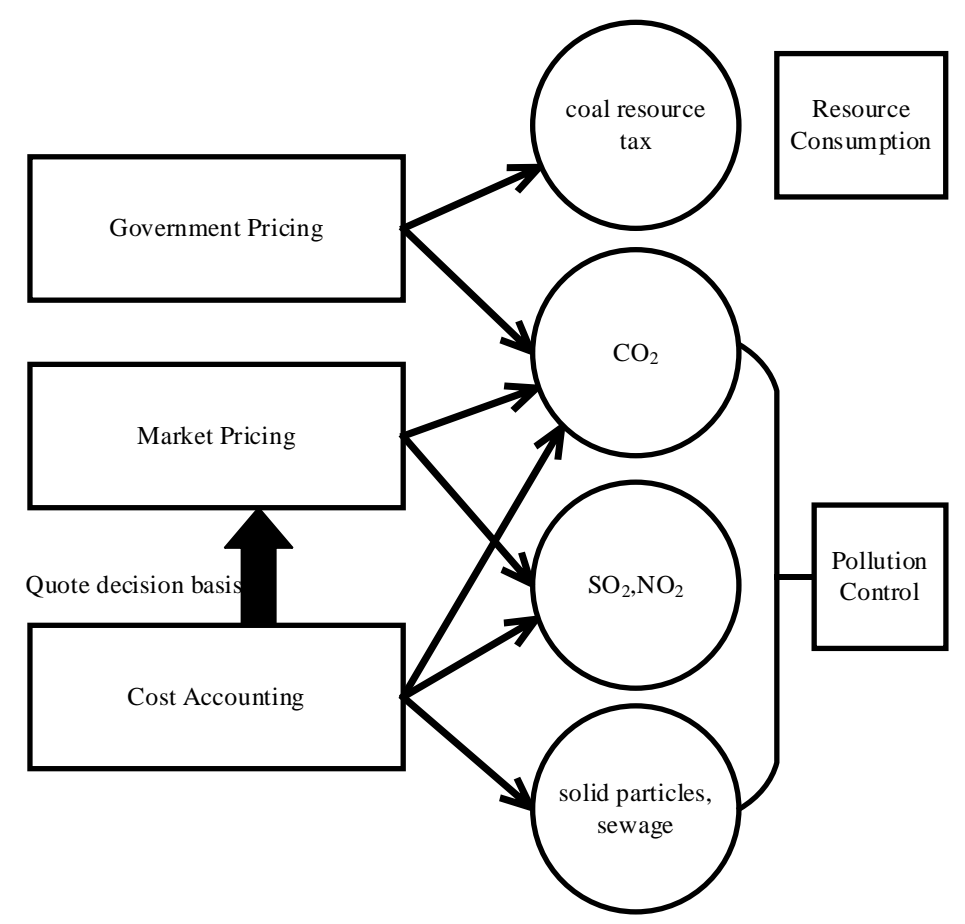

Figure 4. Pricing methods and scope.

Table 9. Results summary.

\begin{tabular}{ccccccc}
\hline Method & $\mathrm{Tax}$ & $\mathrm{CO}_{2}$ & $\mathrm{SO}_{2}$ & $\mathrm{NO}_{\mathrm{x}}$ & $\mathrm{PM}$ & Sewage \\
\hline$(1)$ & 3 & 50 & 631 & 631 & 1832.1 & 28 \\
$(2)$ & 3.5 & 57 & 137 & 137 & 1023 & 3 \\
$(3)$ & 3 & 50 & 116.7 & 272 & 915.7 & 1.8 \\
\hline
\end{tabular}

Table 10. The pricing scope of Tax and $\mathrm{CO}_{2}$.

\begin{tabular}{cc}
\hline Carbon Tax (Yuan/t) & $\mathrm{CO}_{2}($ Yuan/t) \\
\hline $3-3.5$ & $50-57$ \\
\hline
\end{tabular}

Table 11. Range of pollution control pollutants.

\begin{tabular}{cccc}
\hline $\mathrm{SO}_{2}$ & $\mathrm{NO}_{\mathrm{x}}$ & $\mathrm{PM}$ & Sewage \\
\hline $116.7-137$ & $137-272$ & $915.7-1023$ & $1.8-3$ \\
\hline
\end{tabular}

Unit: Yuan/t. 
part of the sale of electricity, the province belongs to the sale of electricity side, due to the pollutants of local power generation also needs conversion costs equivalent, in the sale of electricity required to add this part of the cost equivalent to ensure their maximum benefit.

\section{Conclusions}

This paper proposes three calculation methods for cost equivalent, the method that analogy to estimate the carbon tax method is relatively simple, but it's mainly based on national policy and specific circumstances of the plants.

The market bidding method suitable for $\mathrm{CO}_{2}, \mathrm{SO}_{2}$ and $\mathrm{NO}_{\mathrm{x}}$, which are all spread farther. In the bidding process needs to take into account the impact on adjacent or similar cause cross contamination between areas, in order to ensure the equivalent accuracy, the cost of price bidding needs to be taken into account.

The cost is determined by costing equivalent calculation method which is at the source of the emissions estimates, estimates more accurate. Calculation in this paper is based on the available data, if there is enough data to support able to calculate the difference between the whole generators set emission reduction benefits within a certain period, the data can be more accurate. Depending on the different geographical units to get different statistics for the purchase and sale of electricity cost equivalent decision-making, can maximize the benefits.

\section{References}

[1] Shi, Y. (2011) Research on the Performance Evaluation of Energy-Saving and Emission Reduction in Electric Power Industry. North China Electric Power University (Baoding).

[2] Wang, Z.X., Pan, L. and Peng, J. (2005) Analysis of Current Status, Cost and Policies of Power Sector $\mathrm{SO}_{2}$ Emission Control. Research of Environmental Sciences, 18, 11-20.

[3] Wang, Z., Xiao, Z.Y. and Dai, Y. (2009) CDM Project of Large-Scaled Animal Farms in Arid Region and Estimation of Greenhouse Gas Mitigation. Journal of Ecology and Rural Environment, 25, 1-7.

[4] Wang, Y. and Zhang, J.H. (2011) The Foreign Literature on Carbon Tax: A Review Based on the Design and Institutional Arrangements of Carbon Tax. Social Sciences in Guangdong, 1, 13-18.

[5] Yong, G. (2012) Study on Pollution Charge Standard Based on Pollution Abatement Costs. Nanjing University of Science \& Technology.

[6] Yan, L., Yang, J.T. and Xue, W.B. (2008) The Cost-Benefit Analysis of WET FGD FOR Power Plant Units. Energy Environmental Protection, 22, 6-9. 